\title{
«КУЛЬТУРНЫЕ БАРЬЕРЫ» ИННОВАЦИОННОГО РАЗВИТИЯ В ВОСТОЧНОЙ ЕВРОПЕ
}

\section{C.В. КСЕНЗОВ}

кандидат исторических наук, доцент кафедры международного бизнеса, Белорусский государственный экономический университет, г. Минск

\section{Аннотация}

Научная дискуссия с Е. Ясиным по поводу его тезиса о необходимости и способах «преодоления культурного барьера» в инновачионном развитии Восточной Европы. Проводятся исторические аналогии и отслеживается ход институциональных изменений в России, Беларуси и Украине. В качестве культурного барьера инновационного развития подвергнуты анализу традиции авторитаризма; бюрократизма; правового нигилизма; клиентелизма. Предложена концепция преодоления «культурных барьеров» инноващий на основе теории институциональных матриц.

\section{Abstract}

Scientific discussion with Yevgeniy Yasin on his thesis on the need and ways "to overcome the cultural barrier" in the innovative development of Eastern Europe. The progress of institutional changes in Russia, Belarus and Ukraine are drawing with historical analogies. The tradition of authoritarianism; bureaucracy; law nihilism; clientelism are analyzed as a cultural barrier of innovative development. The concept of the innovation "cultural barriers" overcoming is formulated. It based on the theory of institutional matrices.

\section{ВВЕДЕНИЕ}

В ряде публикаций Е. Ясин актуализировал проблемы инновационного развития в восточной Европе в контексте взаимосвязи и взаимовлияния с аналогичными процессами в Западной Европе и Северной Америке. [1] Исторический подход позволил автору нарисовать панорамную картину произошедших и происходящих общественноэкономических явлений этого региона. Выделение «культурного барьера» в инновационном развитии является интересной находкой, и представляет собой поле для дискуссий.

Вступить в научную дискуссию нам захотелось по поводу тезиса о необходимости и способах «преодоления культурного барьера». Проводя исторические аналогии и отслеживая ход институциональных изменений в России, Е. Ясин выделяет в качестве культурного барьера инновационного развития - традиции авторитаризма; бюрократизм; правовой нигилизм; клиентелизм. Он считает что: «Устранение этих недостатков жизненно необходимо. Но можно ли решить эту задачу с помощью государственного насилия, возобновления традиционной системы распоряжения властью и восстановления контроля власти над собственностью? И стоит ли таким образом учитывать национальные культурные традиции? Мне кажется очевидным, что в данном случае бессмысленно выбивать клин клином. Наш исторический опыт свидетельствует о том, что борьба со слабостью государства подобными методами неизменно приводила к восстановлению деспотического правления, которое и плодило эти недостатки, порождая новые кризисы». [2] Целью статьи является рассмотреть данные проблемы с помощью исторического подхода. Выяснить специфику функционирования данных институтов в России, Беларуси и Украине. Определить влияние «культурного барьера» на инновационное развитие и предложить концепцию их преодоления на основе теории институциональных матриц.

\section{РЕЗУЛЬТАТЫ И ИХ ОБСУЖДЕНИЕ}

А.И. Пригожиным инновация понимается как целенаправленное изменение, которое вносит в среду внедрения (организацию, поселение, общество и т.д.) новые, относительно стабильные элементы. [3] Последние могут быть исключительно материальными или социальными, но каждый из них представляет новшество, т.е. предмет нововведения. Нововведение (инновация) - переход некой системы из одного состояния в другое, включающий в себя и перевод, т.е. инициируемые и контролируемые изменения. С термином «инновация» тесно связаны понятия «новшество», «изобретение», «открытие», являющиеся продуктами креативности. Но если креативность подразумевает выдвижение новых идей, то отличительным признаком инновации является воплощение их на практике. Отсюда следует, что инновация не является таковой до того момента, пока она успешно не внедрена и не начала приносить прибыль. Поэтому в узком, экономическом, смысле инновация есть продукт (новая конструкция, технология, организационный прием и т.п.), воплощенный в товаре, который пользуется спросом на рынке в силу своей новизны.[4]

Инновационный процесс и инновационный климат являются понятиями характеризующими среду, в которой происходит рождение и внедрение изобретения. Инновационный процесс это процесс последовательного превращения идеи в товар, проходящий этапы фундаментальных и прикладных исследований, конструкторских разработок, маркетинга, производства и сбыта. В него, по мнению Чепуренко А.Ю., обязательно входят организационноэкономические и социокультурные условия нововведения. [5] Но это все равно очень узкий взгляд на данное явление. Для того, чтобы заработала инновационная экономика, должны эффективно работать политические, правовые и социо-экономические институты. Более того, институты культуры должны соответствовать и не противоречить нововведениям. Когда Е. Ясин и Н. Лебедева предлагают создавать новые социо-культурные институты, [6] то это напоминает усилия коммунистов в СССР по борьбе с религией и насаждению «научного атеизма». Заимствовать из У- 
матрицы отдельные политические, экономические и правовые институты, конечно необходимо, но «создавать» новую культуру бесполезно.

Инновационный климат - понятие микроэкономики, связанное с формированием обстановки, позволяющей человеку чувствовать себя свободным, мотивированным, готовым к творческой работе. Выделяют следующие организационные отношения, позволяющие в полном объеме использовать творческий потенциал:

• поддержка инновационной деятельности руководством;

- содействие экспериментаторству на всех уровнях;

- высокий уровень коммуникаций и их постоянное совершенствование;

• использование комплексных мотивационных систем;

- применение соучаствующего стиля управления, что предупреждает сопротивление персонала технологическим и организационным нововведениям;

- непрерывное пополнение сотрудниками своих знаний. [7]

Е. Ясин и Н. Лебедева пишут: «Сейчас уже многие понимают, что обязательным условием инновационных преобразований является преодоление культурного барьера, прежде всего традиционно патерналистских и иерархических моделей на всех уровнях, губящих всякую инициативу и творческие порывы и в итоге препятствующих рыночным процессам. Они зиждутся на ценностях власти, безопасности, конформизма». [8]

На самом деле «преодоление культурного барьера» не является самой актуальной задачей инновационного развития. Теория институциональных матриц четко показывает, что является главным, а что второстепенным. Базовые правовые, политические и экономические институты один раз сформировавшись не подвержены значительным изменениям во времени. Соответственно в создании условий для инновационного развития Восточной Европы существенную роль могут сыграть комплементарные институты из У-матрицы. Среди правовых институтов, безусловно, следует выделить защиту интеллектуальной собственности. Проблема состоит не в формальном введении правил этой защиты принятых в Западной Европе и США, а в полноценном соблюдении этих правил как бюрократией, так и участниками инновационного процесса. Воровство программных продуктов является нормой на просторах Восточной Европы, и когда заводится уголовное дело по этому случаю, на форумах в Интернете появляется вопрос: «А на компьютерах прокуратуры, следствия и суда стоит лицензионный Windows?».

Проблема внедрения комплементарных экономических институтов также сводится в первую очередь к неформальным практикам. Можно скопировать правила функционирования венчурного фонда, и даже допустить частное предпринимательство в этой сфере. Гораздо труднее приспособить деятельность участников инновационного процесса к реалиям институциональной среды. Любой восточноевропейский ученый, сталкивавшийся с процессом получения грантов из отечественных фондов, расскажет о том, сколько времени уходит на преодоление бюрократических барьеров, а сколько на творчество. Соотношение будет всегда в пользу первого фактора инновационного процесса. Когда трансакционные издержки научного труда превышают 50 \%, не может быть и речи о полноценном инновационном развитии.

Теория институциональных матриц в социокультурной сфере выделяет идеологию. И это тот резерв, который должен помочь в инновационном развитии Восточной Европы. Использовать этот ресурс непросто, так как всякая идеология должна опираться на конкретное ее материальное воплощение. Иначе это будет просто болтовня.

Соответственно идеология инновационного развития реализуется через систему концептуально-теоретических взглядов и идей, выражающих основные приоритеты, интересы, цели, идеалы и ценности инновационного сообщества и его организаций. Данная идеология должна стать неотъемлемой частью социальной действительности, политического и духовного бытия общества, специфическим ориентационно-ценностным сознанием, выражающим интересы различных групп инноваторов и общества в целом. Инновационная идеология становится организующим фактором, инструментом консолидации на базе определенных идей, мировоззренческих принципов и ценностей. Система принципов и ценностей выполняет следующие задачи: дает теоретическое обоснование действий инноваторов, пробуждает эти действия в массовых масштабах, утверждает в их рядах веру в собственные силы, организует и сплачивает их. Новые исторические условия требуют тщательной разработки основных понятий инновационной идеологии.

В разработке данной идеологии следует опираться на понятие «духовного императива» В. Ксензовой. Она пишет: «И здесь принципиально важным для человеческого общества является то, что в процессе трансформации энергетического потенциала в действие (духовное, социальное, экономическое) человек начинает познавать себя и окружающий его мир. Т.е. фиксировать, кодировать и передавать постоянно накапливаемое знание. С одной стороны, это приводит к созданию институтов-носителей информации, роль которых в социуме хорошо описана в различных институциональных концепциях. С другой стороны, актуализирует специфический вид энергии - интеллектуальную энергию. Именно интеллекту как носителю этого принципиально отличного от других видов виду внутренней энергии человека и принадлежит важнейшая роль в переходе духовной эволюции человечества на качественно новый уровень». [9]

Авторитаризм и бюрократизм. В Древней Руси традиции авторитаризма закладывались в ходе установления княжеской власти. Институтом феодальной демократии служило вече. В ходе монгольского ига на территории современных России и Украины демократические славянские институты были утрачены. Авторитаризм пустил глубокие корни. В тоже время в Великом княжестве Литовском вплоть до конца XVIII институты феодальной демократии успешно функционировали, трансформировавшись в решение политических и экономических проблем парламентским путем. К чему привел расцвет парламентской феодальной демократии в виде «liberum veto"? К еe гибели в ре- 
зультате разделов Речи Посполитой авторитарными Российской империей, Пруссией и Австро-Венгрией. Причем в военно-техническом развитии эти феодальные образования не уступали другим европейским государствам.

В России парламент (Дума) появляется только в 1906 году, а демократия побеждает только в феврале 1917 г. Причем именно победа демократических сил ослабила государственную машину и привела к власти коммунистов. Была ли демократия в СССР? Если рассматривать демократию как «власть большинства избирателей», то безусловно да. Почему большинство поддерживало советскую власть? Демагогические обещания светлого будущего, бесплатная раздача собственности, формальное социальное равенство, - безусловно, соответствовали клиентелистской психологии общества. Почему же это большинство позволило благополучно скончаться власти коммунистов в 1991 году? Ведь Ельцин пришел к власти отнюдь не демократическим путем, а в результате государственного переворота. Народ устал от ожидания светлого будущего, захотел полноценно владеть собственностью и разочаровался в формальном равенстве. Следовательно, институциональных изменений в СССР желала как партийная бюрократия, так и большинство народа. Таким образом, реформы 90-х годов в Восточной Европе - это реализация тайных желаний советской бюрократии о собственности и власти, объективно обусловленные всем ходом развития СССР, и, прежде всего Российской Федерации.

Каков результат реформ и перспективы инновационного развития в России, Украине и Беларуси. В Беларуси были сохранены многие элементы советской системы управления, прежде всего, вертикальная структура. Решения, принятые на верху вертикали обязательны для исполнения внизу. Принуждение к исполнению формальных и неформальных правил государственного управления жесткое и бескомпромиссное. Неформальные правила в Беларуси присутствуют, но не доминируют. В Беларуси создана система «авторитарной демократии». Покоится она на власти бюрократии, интересы которой защищает президент. С другой стороны президент защищает интересы народа, заставляя бюрократию действовать не только в своих интересах. Таким образом, бюджетные деньги расходуются достаточно эффективно, что позволяет социально защищать проблемные слои населения. Недостаток этой системы - отсутствие свободы. Это прежде всего сказывается на инновационном развитии.

Институциональные изменения в постсоветской России и Украине были более радикальными, чем в Беларуси, и, соответственно, привели к важным революционным последствиям. В России и Украине пошли по пути коренной ломки советских институтов и насаждению импортированных. Практически все формальные институты рыночной экономики были внедрены в первой половине 90-х годов. Такой быстрый импорт институтов не мог пройти безболезненно.

Введение института частной собственности не сопровождалось полноценным функционированием институтов гарантирующих экономическую свободу и равенство всех перед законом. В результате приватизации государственная собственность досталась немногочисленной прослойке граждан обладавших полнотой информации. Олигархический капитализм уничтожил многочисленные социальные достижения советского общества и узаконил социальное и экономическое неравенство. Приватизация и «бандитский» капитализм подорвали престиж института государства и сделали его неэффективным. А.И. Соловьев отмечает: «На историческом фоне движения state-государственности качество правления на “острове Россия” выглядит не слишком впечатляющим: дефицит даже не эффективности, а элементарной рациональности построения государственных институтов; низкоэффективная госадминистрация и масштабная коррупция; периферийное по отношению к власти положение граждан и беспредел теневого лоббизма; авторитарноцентрализованный стиль управления с безраздельным влиянием политико-бюрократических коалиций и холопством конституэнтов; беспомощность и зависимость от власти судебной системы; деинституализированная публичная сфеpa». [10]

Правовой нигилизм и клиентелизм. Исторически у восточных славян существовало пренебрежительное отношение к праву. Точнее к формальным правилам, устанавливаемым государством. А вот большинство неформальных правовых обычаев свято соблюдались. А.И. Соловьев пишет: «Полагаю, что из широкого перечня черт гражданской культуры, возможно, самыми разрушительными для российской государственности архетипами следует считать правовой нигилизм и попечительское отношение к власти. Первый опирается на дефицит внутренней солидарности населения, отражающий устойчивые (социальные, этнические, ценностные и проч.) расколы общества и заставляющий человека воспринимать социум как набор разнообразных локалитетов со своими незыблемыми порядками». [11]

Не слишком уважительное отношение к кодифицированному праву, понимание его моральной неполноценности как всеобщего способа общественного устройства веками сопрягалось и со страхом перед властями, пониманием законов как инструмента, закладывающего в “служение” обществу корыстные и неправедные интересы правящего класса. Соединяясь же с пониманием того, что «до Бога высоко, а до царя далеко», российская культура утвердила устойчивое стремление людей к выдвижению собственных схем и моделей правления. Такой полюс российской ментальности провоцирует неискоренимый внутренний анархизм (не исключающий, а провоцирующий пассивность и индифферентность), внутреннюю непримиримость человека к альтернативным вариантам установления порядка. Неудивительно, что в результате россиянин всегда оказывался «или выше закона, или ниже и почти никогда» был неспособен «ценить закон за его специфическую функцию», воспринимать его как необходимый для жизни в обществе «этический минимум». [12]

В рамках этой традиции введение в 90-е годы формальных правил и институтов рыночного хозяйства не привело к эффективности последнего. «Рыночная революция» характеризовалась тем, что старые традиции и нормы (прежде всего неформальные) продолжали инерционно существовать, а новые рыночные формальные правила не были сразу освоены, восприняты, не было эффективного механизма их исполнения. Последствия неформальной институционализации многообразны. В первую очередь это приводит к увеличению трансакционных издержек, теневой сектор 
увеличивается, государственные структуры сращиваются с преступными, инвестиции связаны с риском. Если неформальные правила в ходе институциональных изменений сформировались, то их трудно отменить.

Е. Ясин считает, что клиентелизм является важнейшим «барьером» инновационного развития в России. У клиентелизма, как и у коррупции, в силу сложности этого социального явления нет общепринятого определения. С позиции институционализма Смирнов Н. В. определяет коррупцию как «структуру управления оппортунистическим поведением в публичных институтах». [13] Под клиентелизмом можно понимать социальное явление, характеризующееся формированием специфических отношений доминирования, господства и подчинения. В этих отношениях одна из сторон (патрон) является покровительствующей, вторая (клиент) покровительствуемой. Статус сторон этих отношений весьма изменчив: патроны и клиенты взаимозависимы, в некоторых случаях, например, клиенты имеют возможность вынудить патрона действовать в их интересах, ущемляя его собственные. Право на занятие бизнесом в России, Беларуси и Украине можно получить исключительно от соответствующего чиновника [14], который фактически и становится патроном будущего предпринимателя. В соответствии с институциональной инерцией и гражданам, и чиновникам, и бизнесменам клиентелисткие отношения ближе и понятнее, чем демократические, основанные на законе. Этот вывод подтверждается определенными тенденциями развития бизнеса в восточной Европе, который от прямого подкупа представителей власти и контроля криминальных структур, часто обозначаемого как наличие «крыш», перешел не к правовым отношениям с властью, а к практике долгосрочных альянсов между конкретными чиновниками и конкретными бизнесменами, нередко корпоративного типа, когда власть и бизнес реализуют общие интересы.

Сегодня в России и Украине трудно найти сферы, где не было бы тех или иных теневых проявлений. Либерально-рыночные реформы привели к формированию черно-белого рынка, в котором теневая экономика является устойчивым элементом. Вместо конкурентного рынка возник государственно-монополистический капитализм олигархического типа, создав широкие возможности социально паразитического рентоориентированного поведения «армии бюрократии».

\section{ВЫВОДЫ}

Итак, барьер «Ясина» налицо. Традиции авторитаризма, бюрократизм, правовой нигилизм, клиентелизм действительно присутствуют в Восточной Европе XXI века. Нужно ли придерживаться рецепта Е.Ясина и крушить барьеры? Давайте вспомним, куда вели Россию логичные и обоснованные западноевропейскими учеными теории. В. Ленин предлагал на основе теории марксизма «ломать барьеры» и строить коммунизм. Е. Гайдар «ломал барьеры» и строил рыночную экономику по учебнику «Economics».

В чем главная ошибка Ясина-Ленина-Гайдара? Нельзя что-то ломать даже на основе хорошей теории. А крушить культурные барьеры бесполезно. Именно институты культуры являются наиболее устойчивыми и не подверженными быстрым изменениям. Для Е. Ясина демократия - это абсолютное благо. Но как показано ранее попытки ввести демократию вели Россию к катастрофе. Для Е. Ясина демократия - это путь к инновациям. Самых больших демократических достижений в Восточной Европе достигла современная Украина. Является ли она лидером по инновациям?

С другой стороны, суждения Е. Ясина имеют под собой основания, так как экономику стран Восточной Европы не назовешь инновационной. И барьеры нужно преодолевать, просто для того, хотя бы, чтобы сохранить суверенитет. Власть это поняла после украинских событий.

Какой же рецепт можно предложить для того, чтобы «культурные барьеры» не мешали инновационному развитию России, Беларуси и Украины? Авторитарные правители должны понимать, что важнейшим условием инновационного развития является академическая свобода и высокая оплата труда ученых. Ясно, что полноценной свободы в университетах и научных институтах допустить власти не могут. Но нужно стремиться к ее уровню, который был в России до 1917 года. Ректоры назначаются властями, но на внутреннюю свободу научных учреждений никто посягать не должен.

Оплата труда ученых должна превышать оплату аналогичного труда в странах Западной Европы и США. Только в этом случае есть какие-то гарантии, что прекратится отток наиболее талантливых работников умственного труда. Фактически это будет компенсация за работу в условиях неполной свободы.

Важно понять, что прикладные разработки должны финансировать бизнес-структуры. Именно они заинтересованы в получении прибыли от их внедрения. Бюджетные ресурсы тогда будут расходоваться на содержание специалистов в области фундаментальных наук, что позволит государству выплачивать высокую заработную плату преподавателям университетов. В условиях автократии провести данные реформы достаточно легко. Ведь главные противники этих преобразований - бюрократы. А они подчиняются и полностью зависят от авторитарного правителя.

Гораздо тяжелее преодолеть клиентелисткие традиции. Экономика «отката» настолько прочно укоренилась на просторах восточной Европы, что даже воли правителя недостаточно, чтобы быстро устранить этот «культурный барьер». «Распиливание» денег выделяемых на научные проекты настолько стало неформальной практикой, что порядочным ученым просто стыдно идти в такие «научные коллективы». Существующие НИИ обслуживают бюрократию из своих министерств, которая устанавливает правила. Большая часть времени ученого уходит на оформление заявки на грант и отчетной документации, составление справок для бюрократии. Трансакционные издержки научного труда превышают 50\%. Реальный рецепт по преодолению этого барьера - уход от государственного финансирования прикладных разработок. Частный предприниматель кровно заинтересован в снижении издержек и не позволит «распиливать» деньги выделяемые на инновации. 
Вторая проблема инновационного развития - предпринимательство. Кто будет проявлять инициативу по внедрению разработок ученых? В Х-экономике логично было бы надеяться на государственное предпринимательство. И в условиях тоталитарного политического режима СССР так и было. Но как показывает опыт успешного инновационного развития стран с X-экономикой (Япония, Южная Корея, Китай, Сингапур) идеальным является сочетание государственного и частного предпринимательства. Причем в сфере инициативы со стороны бюрократии очень важна роль элиты. Собственный пример и воспитание подчиненных в духе патриотизма, понимания национального значения успешного инновационного развития страны приводят к положительным результатам. Но, конечно, жесткий государственный антикоррупционный контроль в Х-матрице еще никому не мешал. Частные предприниматели, которые будут успешными во внедрении инноваций в Х-экономике должны быть тесно связаны с государственной бюрократией. Так как креативные проекты всегда нестандартны и всегда противоречат предыдущему опыту и, соответственно, предыдущим инструкциям, то только личные связи частного бизнеса могут позволить преодолеть бюрократические барьеры.

Итак, мы видим, что сущность инновационного процесса в Х- и У-экономиках значительно отличается. В ходе исследования и внедрения новшества в У-экономике главным является изобретатель (ученый) и предприниматель (частное лицо). Их индивидуализм поощряется системой защиты интеллектуальной собственности и прибылью. В Хэкономике исследователь работает на государство, и именно государственная бюрократия дает добро на финансирование и внедрение новшества. Даже в случае частного предпринимательства в сфере инноваций необходимо одобрение бюрократии и получение разрешения на процессы получения патента, лицензии и т.п.

Таким образом, господин Ясин, не в демократии дело, а в сущности функционирования Х и У - экономик. Простые рецепты - давайте будем все копировать у демократических стран - не годятся. Если сравнивать институциональные Х и У - матрицы, то уместно сравнение с мужчиной и женщиной. Да, основные органы тела у мужчины и женщины подобны, поэтому многие болезни лечатся идентично, отличаются лишь дозы лекарств. Но если гинеколог начнет предписывать мужчине, то, что нужно назначать женщине, то результатом станет коллапс. Вот в роли такого гинеколога выступает уважаемый профессор Е. Ясин. Его рецепты взяты из женской У-экономики, а назначить лечение он хочет мужской Х-экономике.

\section{ЛИТЕРАТУРА}

1. Ясин, Е.Г. Сценарии развития России на долгосрочную перспективу / Е. Ясин.- Москва: Фонд «Либеральная миссия», 2011; Ясин, Е. Снеговая М. Институциональные проблемы России в мировом контексте // Вопросы экономики. - 2010. - № 1. - С. 32-49; Ясин, Е.Г. Институциональные ограничения модернизации, или приживется ли демократия в России? //Вопросы экономики. - 2011. - №11. - С.4-24.

2. Ясин, Е. Приживется ли демократия в России / Е. Ясин. - М.: Фонд «Либеральная миссия», 2005. - С. 226.

3. Пригожин, А.И. Методы развития организаций /А.И. Пригожин. - М.: МЦФЭР, 2003, с. 770.

4. Лебедева, Н.М. Культура и инновации... К постановке проблемы /Н.М. Лебедева, Е.Г. Ясин //Форсайт. 2009. - № 2. - С.16.

5. Чепуренко, А.Ю. Малое предпринимательство в социальном контексте. - М.: Наука, 2004.

6. Лебедева, Н.М. Культура и инновации... К постановке проблемы /Н.М. Лебедева, Е.Г. Ясин //Форсайт. 2009. - № 2. - С.18.

7. Харин, А.А. Управление инновациями / А.А. Харин, И.Л. Коленский - М.: Высшая школа, 2003.

8. Лебедева, Н.М. Культура и инновации... К постановке проблемы /Н.М. Лебедева, Е.Г. Ясин //Форсайт. 2009. - № 2. - С.24.

9. Ксензова, В.Э. Влияние духовного императива на формирование системы институтов-коридоров хэкономики / В.Э. Ксензова, С.В. Ксензов // Journal of Institutional Studies, 2014. - № 1. - С.113.

10. Соловьев, А.И. Цивилизационное пространство государственности (Противоречия западной и отечественной моделей) / А.И. Соловьев //Общественные науки и современность. - 2010. - № 3. - С.102.

11. Соловьев, А.И. Цивилизационное пространство государственности (Противоречия западной и отечественной моделей) / А.И. Соловьев //Общественные науки и современность. - 2010. - № 3. - С.103.

12. Федотов, Г.П. Русское религиозное сознание: киевское христианство Х-ХІІІ вв. /Г.П. Федотов // Актуальные проблемы Европы. - 1998. - № 3. - С.139.

13. Смирнов, Н. В. Институциональная природа коррупции /Н. В. Смирнов // Общество и экономика. - 2010. № 2. - С. $87-104$.

14. Клямкин, И. М. Теневая Россия: Экономико-социологическое исследование / И. М. Клямкин, Л.М. Тимофеев - М.: Рос. гос. гуманит. ун-т, 2000. - С. 93.

Статья поступила в редакцию 5 июля 2015 года. 